\title{
Familial meningiomas
}

\author{
ROBERT J. JOYNT AND GEORGE E. PERRET
}

From the Departments of Neurology and Surgery, State University of Iowa, Iowa City, Iowa, U.S.A.

The familial occurrence of brain tumours is extremely rare except for neurofibromas in von Recklinghausen's disease and cerebellar haemangioblastomas in Lindau's disease. There have been rare instances of intracranial gliomas, including astrocytomas, medulloblastomas, and oligodendrogliomas, occurring in two or more members of the same family (Munslow and Hill, 1955; Kjellin, Müller, and Åström, 1960; Leavitt, 1928; and Parkinson and Hall, 1962). Kjellin and his associates (1960) have reviewed previous reports and added seven of their own, making a total of 33 instances in which brain tumours usually not considered hereditary had occurred in two or more close relatives.

Meningiomas occurring in relatives have been noted in von Recklinghausen's disease and Lindau's disease. The association of meningiomas and multiple neurofibromatosis in the same patient was noted by Cushing and Eisenhardt (1938), and the occurrence of this combination in a father and daughter was reported by Davidoff and Martin (1955). Ectors and van Bogaert (1953) reported the removal of meningiomas from the occipital region of a brother and sister, and were later able to find clinical evidence of multiple neurofibromatosis. Patterson and Anderson (1940) operated on a supratentorial angioblastic meningioma in one member of a family whose brother and father had cerebellar haemangioblastomas. Wolf and Cowen (1936), in a review of six cases of angioblastic meningioma, suggest that possibly these may not be of meningeal but of vascular origin, and discuss the possibility that they may be related to the cerebellar haemangioblastomas seen in Lindau's disease. This view is buttressed by the case report of Rochat (1931) describing a supratentorial haemangioblastoma in one member of a family with well-established Lindau's disease. Thus, the familial meningiomas reported in Lindau's disease may not be of meningeal origin.

The only instances, to our knowledge, of the familial occurrence of meningiomas without evidence of neurofibromatosis or Lindau's disease were those reported by Gaist and Piazza (1959) in a brother and sister, and a report by us (Joynt and Perret, 1961) in a mother and daughter. Recently, we en- countered a similar situation, again in a mother and daughter.

\section{CASE REPORTS}

CASE 1 The mother, aged 59, suffered from headaches for several years but was otherwise well until one day before her admission to Mercy Hospital, Cedar Rapids, Iowa. She complained of extreme fatigue and vomiting. On examination, she was lethargic but answered questions when stimulated. Her heart rate was $63 /$ minute and was irregular. She had bilateral ankle clonus but otherwise the extremities were flaccid. The spinal fluid was bloody with 3,750 R.B.C.s/c. $\mathrm{mm}$. and the protein was $48 \mathrm{mg}$. per $100 \mathrm{ml}$. The patient died the day after admission. Clinical diagnosis was cerebral haemorrhage.

The necropsy findings were not remarkable except for the brain. There was an encapsulated tumour $6-7 \mathrm{~cm}$. in diameter located under the left frontal lobe, firmly attached to the dura. The tumour compressed but did not invade the frontal lobe. It was described as 'pink-grey' in colour and 'rubbery' in consistency. The central portion of the tumour was soft and haemorrhagic. There was an extensive pontine haemorrhage.

Microscopic sections (Fig. 1) of the tumour consisted of spindle-shaped cells arranged in strands. There were

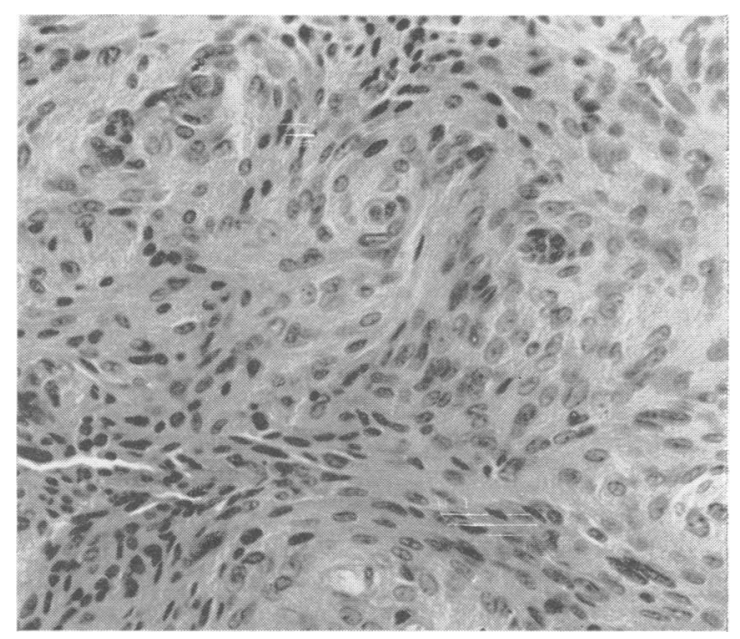

FIG. 1. Microscopic section of tumour found at necropsy in the mother (case 1). 
frequent areas of whorl formation. The nuclei were round to elongated with vesicular nucleoplasm and small nucleoli. There were no psammoma bodies, and no calcification. There was no evidence of sarcomatous change. The impression was meningothelial meningioma.

CASE 2 The daughter of case 1, a 36-year-old white woman, was seen at the University Hospital for intermittent headaches for two years. They were most severe in the morning and were occasionally accompanied by nausea and vomiting. She also noted that a 'strange' taste accompanied the headaches. For one year before her admission she had increasing difficulty with her vision She had five children, and her periods were regular.

On examination she had high grade papilloedema and hyperactive deep tendon reflexes. There was anosmia on the right side.

The radiographic findings showed enlargement of the sella turcica with demineralization of posterior clinoid processes suggesting increased intracranial pressure.

The right carotid angiogram was abnormal with displacement of the anterior cerebral to the left of the midline and showed a venous tumour stain deep in the right anterior fossa.

At operation, a hard, nodular, encapsulated tumour was located under the right frontal lobe arising from the olfactory groove. The tumour was large, extending to the anterior tip of the anterior fossa, back to the sphenoid ridge, and medially beneath the falx.

The patient made an excellent recovery and was asymptomatic six months after the operation.

Microscopic sections (Fig. 2) of the tumour consisted of polygonal and long spindle-shaped cells in a reticular arrangement. The nuclei were quite uniformly round with finely granular nucleoplasm. Numerous psammoma bodies in all stages of development were seen. There were flecks of calcium throughout the tumour which had large areas of degeneration. There was no evidence of

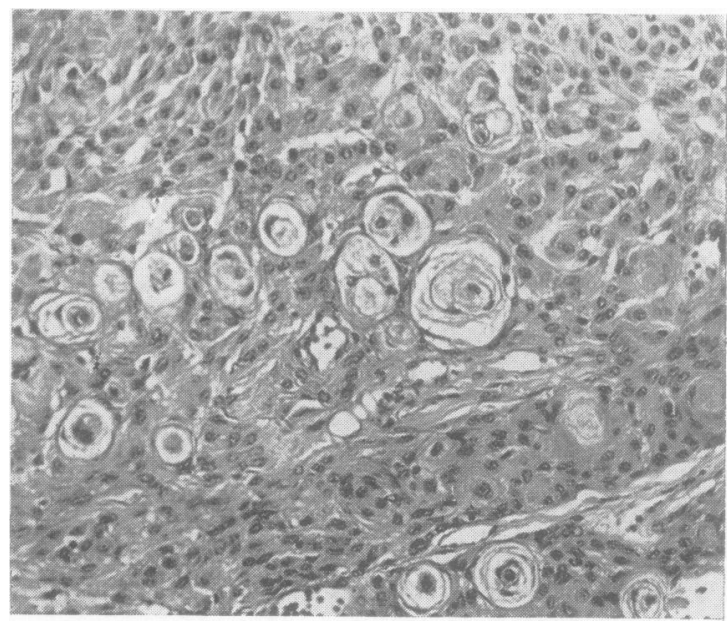

FIG. 2. Microscopic section of tumour removed at operation in the daughter (case 2). sarcomatous change. The diagnosis was meningioma with $\bar{Z}$ numerous psammoma bodies.

The tumours did not have any of the characteristics of a neurofibroma. There was no evidence in $\bar{\varrho}$ either patient of external manifestations of von $T$ Recklinghausen's disease. They did differ in that the daughter's tumour had many psammoma bodies and large areas of degeneration.

\section{DISCUSSION}

The occurrence of meningiomas in close relatives? may be purely coincidental. Also, there may be $\frac{\bar{\sigma}}{\overline{0}}$ evidence of multiple neurofibromatosis which will $\frac{\bar{D}}{\partial}$

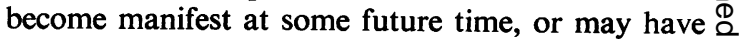
been overlooked in the original examinations. It is फ़. also possible that von Recklinghausen's disease may $\vec{\circ}$ exist in a purely monosymptomatic form and that familial meningiomas are but one variant of that $\vec{\omega}$ disease just as are the bilateral acoustic neurinomas in several generations of the family reported by Gardner and Frazier (1930).

\section{SUMMARY}

Meningiomas occurring in a mother and daught $\stackrel{P}{\overrightarrow{8}} \vec{\omega}$ without evidence of neurofibromatosis were verifie $\Phi_{2}$ 음 the third instance in close relatives. This may be pure coincidence or may be some variant of von Recklinghausen's neurofibromatosis.

The authors are indebted to Dr. Francis M. Skopec fë the details and slides of case 1 .

\section{REFERENCES}

Cushing, H., and Eisenhardt, L. (1938). Meningiomas. Thomas, Springfield, Illinois.

Davidoff, L. M., and Martin, J. (1955). Hereditary combined ڤి neurinomas and meningiomas. J. Neurosurg., 12, 375-384.

Ectors, L., and van Bogaert, L. (1953). Ablation d'un méningiome du trou occipital chez un frère et une soeur. Acta neurol. belg., 53, 193-204.

Gaist, J., and Piazza, Jr. (1959). Meningiomas in two members of the same family. $J$. Neurosurg., 16, 110-113.

Gardner, W. J., and Frazier, C. H., (1930). Bilateral acoustic neuro- $\frac{\vec{\sigma}}{\mathrm{O}}$ fibromas. Arch. Neurol. Psychiat. (Chic.), 23, 266-300.

Joynt, R. J., and Perret, G. E. (1961). Meningiomas in a mother and daughter. Neurology. (Minneap.), 11, 164-165.

Kjellin, K., Müller, R., and Åström, K. E. (1960). The occurrence of ? brain tumours in several members of a family. $J$. Neuropath. exp. Neurol., 19, 528-537.

Leavitt, F. H. (1928). Cerebellar tumours occurring in identical twins. Arch. Neurol. Psychiat. (Chic.), 19, 617-622.

Munslow, R. A., and Hill, A. H. (1955). Multiple occurrences of gliomas in a family. J. Neurosurg., 12, 646-650.

Parkinson, D., and Hall, C. W. (1962). Oligodendrogliomas: simul- 윽 taneous appearance in frontal lobes of siblings. Ibid., 19, I 424-426.

Patterson, G. H., and Anderson, F. M. (1940). Intracranial tumors occurring in three members of a family. Bull. Los Angeles $\mathrm{N}$ neurol. Soc., 5, 218-223.

Rochat, G. F. (1931). Grosshirnangiom bei der Lindauschen (v. Hippelscher) Erkrankung. Klin. Mbl. Augenheilk., 86, 23-27. N

Wolf, A., and Cowen, D. Jr. (1936). Angioblastic meningiomas. N Supratentorial hemangioblastomas. Bull. neurol. Inst. N.Y., 5, $485-514$. 